\title{
Acquisition and extinction of runway performance under escape, avoidance, and partial-avoidance procedures*
}

\author{
NEWELL K. EATON, CHARLES R. CROWELL $\dagger$, and JUDSON S. BROWN \\ University of Oregon Medical School, Portland, Oregon 97201
}

\begin{abstract}
The acquisition and extinction of locomotor responses of rats in a straight alley were examined for groups trained under escape, partial-avoidance, and avoidance procedures. During acquisition, one group (escape) received a 0 -sec delay between being dropped into the alley and the onset of shock; two groups (partial avoidance) had $0.5-$ and 1 -sec delays; and two groups (avoidance) had delays of 2 and 4 sec. On the final day of acquisition, the partial-avoidance rats displayed higher running speeds than either the escape- or avoidance-trained animals. The 4 -sec avoidance group was consistently slower than all other groups. Speeds for all groups decreased during extinction, with rate of decline showing some relation to terminal acquisition level. Relative group performance levels proved to be consistent with a simple arithmetic model based on the assumption that changes in running speeds affect the aversiveness of the situation by altering US duration, CS duration, and effective US length.
\end{abstract}

Beecroft and Brown (1967) have reported an experiment in which the relative effectiveness of three different locomotor-training paradigms (escape, avoidance, and partial-avoidance) was evaluat ed with rats in a straight alley. The escape-trained animals were shocked throughout the runway, whereas avoidance-trained rats were allowed ample time ( 2 or $4 \mathrm{sec})$ to reach the goal prior to shock onset. The partial-avoidance procedure was one in which the interval between a rat's being dropped into the runway and the onset of shock was so short $(1 \mathrm{sec})$ that it always encountered some shock near the goal but could avoid it in earlier alley sections. The 2-sec delay group ran faster than the 4-sec group, which is consistent with the finding that, with rats and goldfish in shuttle tasks, shorter response latencies tend to be associated with shorter avoidance intervals (Low \& Low, 1962; Baum, Jaffe, \& Leclerc, 1971; Bitterman, 1964, 1965). The escape group ran faster than the 4-sec group but slower than the 2-sec group in all segments. Contrary to expectations, however, the partial-avoidance animals ran faster than either the escape- or avoidance-trained Ss. Unfortunately, since their experiment was primarily concerned with the effect of their manipulations upon performance during punished extinction, a statistical analysis of this acquisition data was not provided.

It is not entirely clear why both training procedures which allowed complete avoidance of shock and that which permitted only escape from full-alley shock

\footnotetext{
*This research was conducted at the University of Iowa and supported, in part, by National Institute of Mental Health Research Grants MH 11734-07 and $M H$ 23607-01 to Judson $S$. Brown. R equests for reprints should be sent to Newell $\mathrm{K}$. Eaton, Department of Medical Psychology, University of Oregon Medical School, Portland, Oregon 97201.

+ Now at University of Notre Dame, Notre Dame, Indiana.
}

should be less effective in producing high-speed running than procedures that permitted only partial avoidance. The fact that the partial-avoidance Ss were usually shocked in the last segment of the alley, and might thus be said to be "punished" for running toward the goal, increases the complexity of the problem. In addition, whereas the partial-avoidance animals might be said to have had the advantage of shock reduction and higher general drive level over Ss that avoided entirely, the escape Ss should have had a comparable advantage over the partial-avoidance animals.

The present study was conducted to determine whether the findings of the Beecroft-Brown study could be replicated and supported by statistical analysis, as well as to extend the partial-avoidance paradigm by the use of a shorter shock-onset delay period of $0.5 \mathrm{sec}$. In addition, the effect of the training procedures on regular extinction was investigated since, in the Beecroft-Brown experiment, all groups were punished during extinction.

\section{METHOD}

\section{Subjects}

The Ss were 60 naive female albino rats (Sprague-Dawley derivatives) supplied by Carworth Farms, Inc., Portage, Michigan. They were between 90 and 100 days old at the time the experiment began. They were individually housed in constant-light and -temperature quarters and maintained on an ad lib schedule of food and water.

\section{Apparatus}

The principle components of the apparatus [which has been described in detail elsewhere (Brown, Beier, \& Lewis, 1971)], were a grid-floored runway (183 cm long), a two-level, trapdoor-floored startbox, and a large smooth-floored goalbox. The inside of the goalbox was painted with black and white squares $(2.54 \mathrm{~cm}$ on a side) in a checkerboard pattern. All other surfaces, save the Plexiglas lids, were medium gray, including a 
subpanel under the alley grid. Photocells and infrared light sources, located at the beginning of the runway, and at intervals of $61 \mathrm{~cm}$ thereafter, served in conjunction with ancillary devices to provide measures of running speeds in each of the three $61-\mathrm{cm}$ runway segments. The $60-\mathrm{Hz}$ unscrambled shock was controlled by an autotransformer whose output was fed to the grid floor through a $10-\mathrm{K}$ resistor. The shock voltages reported below were measured by a $2,000-\mathrm{ohm} / \mathrm{V}$ ac meter with a dummy load of $100 \mathrm{~K}$ across the grid to simulate the rat's resistance. Shock-onset delays were timed from the instant of release of the trapdoor floor in the startbox.

\section{Procedure}

Shor tly after being received from the supplier, the rats were handled individually for $3-4 \mathrm{~min}$ and transferred to separate cages. On the day prior to the beginning of the experiment, each animal was again handled for about $2 \mathrm{~min}$. At this time, the Ss were rank-ordered by weight and were randomly assigned, from successive sets of five, to one of five groups scheduled to be trained with delays of $0.0,0.5,1.0,2.0$, or $4.0 \mathrm{sec}$ bet ween the release of the trapdoor floor of the startbox and the onset of shock. With the 0.0 -sec delay, avoidance of shock was impossible; with the $0.5-$ and $1.0-\mathrm{sec}$ delays, only partial avoidance could occur since even the fastest animal could not reach the goalbox in less than $1 \mathrm{sec}$; with the 2.0 - and 4.0-sec delays, complete avoidance was possible on all trials.

On Day 1 of acquisition training, a series of six shaping trials was administered that involved the use of progressively longer segments of the runway. On Trials 1 and 2, the startbox was positioned next to the goalbox so that the animals had to traverse only a few centimeters of grid floor to reach safety. The startbox-to-goalbox distance was increased to $61 \mathrm{~cm}$ for Trials 3 and 4 , and to $122 \mathrm{~cm}$ for Trials 5 and 6. On the last three trials of the day (Trials 7-9) the Ss were required to traverse the entire length of the $183-\mathrm{cm}$ runway plus a few centimeters of the startbox. On shaping, as well as on full-length trials, the assigned delays were in effect. On all trials, animals were confined in the upper part of the startbox for $10 \mathrm{sec}$ prior to being dropped. The shock voltage was set at $40 \mathrm{~V}$ for Trials 1 and 2 , at $45 \mathrm{~V}$ for Trials 3 and 4 , and at $50 \mathrm{~V}$ for all succeeding acquisition trials. The rats were run in four squads of 15 each, 3 per group. Nine full-length acquisition trials were administered daily on Days 2 through 10 , at an inter trial interval of approximately' $10 \mathrm{~min}$. Nine extinction trials, with shock off, were given daily on Days 11 through 16.

Running times in each segment of the alley were recorded on every trial. During extinction, if the animal failed to enter the goalbox within $60 \mathrm{sec}$, it was removed from the alley and, for that trial and all following trials, was assigned a running time of $60 \mathrm{sec}$, equally apportioned among the alley segments.

\section{RESULTS}

\section{Acquisition}

Median running times in each segment of the alley on each day were determined for each rat based on the 3 full-alley trials of Day 1 and on nine trials for all other days. These medians were then transformed into speeds in $\mathrm{cm} / \mathrm{sec}$. The means of these individual medians on each day of acquisition have been plotted by groups for Segments 1, 2, and 3 in Fig. 1.

It is evident from this figure that the partial-avoidance groups (0.5- and 1-sec) tended, in every segment, to reach a higher level of performance than did the other groups. The 4-sec group was, in each case, the slowest, whereas the $0-\mathrm{sec}$ and $2-\mathrm{sec}$ groups fell between the partial-avoidance and the 4-sec condition.

These visually evident differences were confirmed by the results of separate analyses of variance computed for the data of each segment. In every segment, the main effects of groups, days, and their interactions were significant. For the first segment, the three $F$ ratios, respectively, were: $F=17.15, \mathrm{df}=4 / 40 ; \mathrm{F}=58.57$, $\mathrm{df}=9 / 360$; and $\mathrm{F}=6.76$, $\mathrm{df}=36 / 360$. For the second segment, the ratios were: $F=21.46$, $d f=4 / 40$; $F=52.00, \mathrm{df}=9 / 360 ;$ and $F=4.09, \mathrm{df}=36 / 360$. Th ratios derived from the third segment, given in the sams order, were: $F=16.04, d f=4 / 40 ; \quad F=17.86$, $\mathrm{df}=9 / 360 ;$ and $\mathrm{F}=2.79, \mathrm{df}=36 / 360$.

Scheffé follow-up tests performed after analyses of variance of the running-speed data from the last day of acquisition for each segment indicated that Group 1.0 was significantly different from Group 4.0 in all segments and from Group 0.0 in Segments 2 and 3. Group 0.5 differed significantly from Groups 0.0 and 4.0 in all segments. Both Groups 0.5 and 1.0 differed
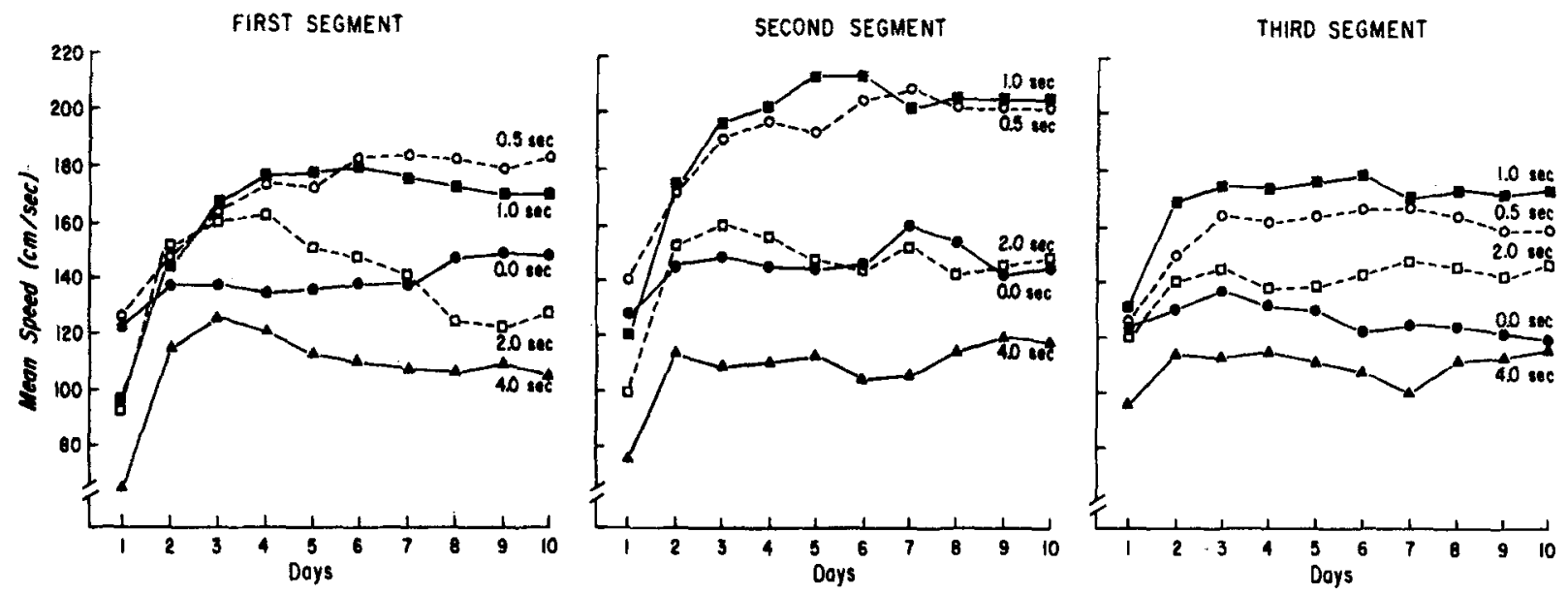

Fig. 1. Mean running speeds in the first, second, and third $61-\mathrm{cm}$ alley segments during acquisition for five groups of rats with shock-onset delays of $0.0 \mathrm{sec}$ (escape training), 0.5 or $1.0 \mathrm{sec}$ (partialavoidance training), and 2.0 or $4.0 \mathrm{sec}$ (avoidance training). 
significantly from Group 2.0 in Segments 1 and 2, while Group 0.0 differed from Group 4.0 in the first segment only. No other differences proved to be significant.

The percentages of shock avoidance on the last day of acquisition for the various groups were as follows: Group $4.0=93.5 \%$; Group 2.0 $=88.9 \%$; and Groups 1.0 and $0.5=0 \%$. Although no rat in the $1-$ or $0.5-\mathrm{sec}$ groups was able to avoid shock entirely, several animals in the 1 -sec delay group reached the goal so quickly that they received shocks of the order of only $0.1 \mathrm{sec}$ in duration.

\section{Extinction}

During the 6 days of extinction, six rats met the criterion of failing to enter the goalbox within $60 \mathrm{sec}$. Two of these were from the 0 -sec group, three from the 0.5 group, and 1 from the 1 -sec group.

Graphic plots of running speeds over the 60 extinction trials revealed a slight tendency for decrements in speed to be directly related to speeds at the start of extinction. However, the Groups by Days interactions approached significance in only the second segment $(F=1.53, \mathrm{df}=24 / 200, p=.06)$. The main effects of groups and of days were significant beyond the .01 level in every section.

To provide a further test of the possibility that extinction rate was proportional to performance level at the end of acquisition, difference scores were obtained between each rat's Day 1 and Day 6 medians. Each of these scores was then expressed as a percentage of the individual rat's Day 1 median, and the resulting group distributions for each segment were subjected to separate one-way analyses of variance. None of the $F$ ratios calculated in this manner approached significance.

\section{DISCUSSION}

The results of the present experiment are consistent with those obtained by Beecroft and Brown (1967) in that the partial-avoidance paradigm yielded higher terminal running speeds than escape or avoidance procedures. Indeed, at the end of training, the four groups in each study that had been trained under identical conditions had attained the same relative ranks in the second and third runway segments, and, over early trials, in Segment 1 also.

Group differences in asymptotic speeds during acquisition cannot be readily explained by appeal either to level of shock-induced motivation in the runway or to the persistence of shock-generated emotionality from one trial to the next. Were these the critical processes, the 0-sec group, which was shocked throughout the runway, should have been faster than all other groups. But that group, in fact, ran more slowly than the partial-avoidance Ss in all segments, and more slowly than the 2-sec avoidance rats in the second and third segments. The superiority of the partial- over the complete-avoidance groups was consistent, of course, with these interpretations, since the former Ss did receive some shock on all trials.

The hypothesis that the obtained speed differences were due to the amount of aversiveness reduction coincident with entry into the goalbox is likewise untenable. If speeds depended heavily upon magnitude of shock reduction, the $0-\mathrm{sec}, 0.5-\mathrm{sec}$, and 1-sec Ss would have performed equally well, inasmuch as all were reinforced, upon entering the goalbox, by identical decreases in voltage from 50 to $0 \mathrm{~V}$.

One promising interpretive possibility is based on the fact that the aversiveness of the situation was inevitably increased by low-speed running and diminished by high-speed locomotion, though in different degrees for different groups. At running times longer than the programmed CS-US interval, the faster the speed, the briefer the shock for all animals. Faster running did not, however, decrease the effective length of the shock region for all groups. This variable would presumably affect the proportion of alley cues that acquired fear-arousing properties, the number of shock onsets and offsets, and perhaps effective shock intensity. In the case of the 0-sec animals, for example, the higher the speed, the briefer the shock, but the effective length of the shock region was not affected by speed. For all other groups, both the duration of the shock and its effective length varied inversely with speed. If a member of the 1 -sec group reached the goal in $3 \mathrm{sec}$, it endured a $2-\mathrm{sec}$ shock present in only the last two-thirds of the $183-\mathrm{cm}$ runway. If it completed its run in $2 \mathrm{sec}$, the shock lasted $1 \mathrm{sec}$ and was present in only the last half of the alley. In addition, for all groups, increased speed produced proportional decreases in exposure to the presumptive fear-arousing apparatus cues.

In an attempt to develop a composite index of speed-contingent changes in aversiveness, effective values of shock duration, shock length, and CS duration were computed and combined in the following manner: First, a range of running times $(1$ to $5 \mathrm{sec})$ that included the shortest and the longest times oberved in this apparatus following the first few shaping trials was chosen. Second, the shock durations resulting from various combinations of possible running times and shock-onset delays were expressed as percentages of the shock duration that would be received by rats in the 0 -sec group on a 5 -sec run. For example, if an animal in the $1-\mathrm{sec}$ partial-avoidance group traversed the alley in $5 \mathrm{sec}$, it received a 4-sec shock, which was $80 \%$ of the maximum duration of $5 \mathrm{sec}$. If the same animal traversed the alley in $2 \mathrm{sec}$, the shock duration was $1 \mathrm{sec}$, or $20 \%$ of maximum. Third, effective shock length under the various delay and running-speed combinations was expressed as a percentage of the full length of $183 \mathrm{~cm}$. Thus, if a rat in the 2-sec group completed a run in $5 \mathrm{sec}$, the effective length of the shock was $109.8 \mathrm{~cm}$, or $60 \%$ of the maximum of $183 \mathrm{~cm}$, whereas on a $3-\mathrm{sec}$ run, the effective length was $33.3 \%$. Effective shock length was, of course, $100 \%$ at all running speeds for the 0 -sec 
group. Fourth, percentages of $C S$ duration, based on time of exposure to apparatus cues, regardless of the presence or the absence of shock, were calculated for all groups, being $100 \%$ at $5 \mathrm{sec}$ and decreasing in direct proportion to reductions therefrom in running time. For example, a $3-\mathrm{sec}$ run yielded a $60 \% \mathrm{CS}$ duration for all groups. Finally, the US-extensity, US-duration, and CS-duration percentages were averaged for each of five running times, and these means have been plotted in Fig. 2. For ease of comparison, a scale of speeds has been included. It should be noted that, for all calculations and comparisons, the simplifying assumption of uniform running speed was made. It can be seen from these functions that, with running time held constant, the longer the shock-onset delay, the lower the computed aversiveness level. Moreover, for any one condition, the higher the speed, the lower the aversiveness index, and vice versa. Although, in Fig. 2., the treatment conditions are associated with different minimal aversiveness levels, those levels are not assumed to determine the actual performance of the groups. Instead, it is assumed that slowing down will be "punished" by increased aversiveness and speeding up will be "reinforced" by reduced aversiveness. Consequently, performance will be determined by the difference in aversiveness between any two points on a function. The greater that difference, and hence the

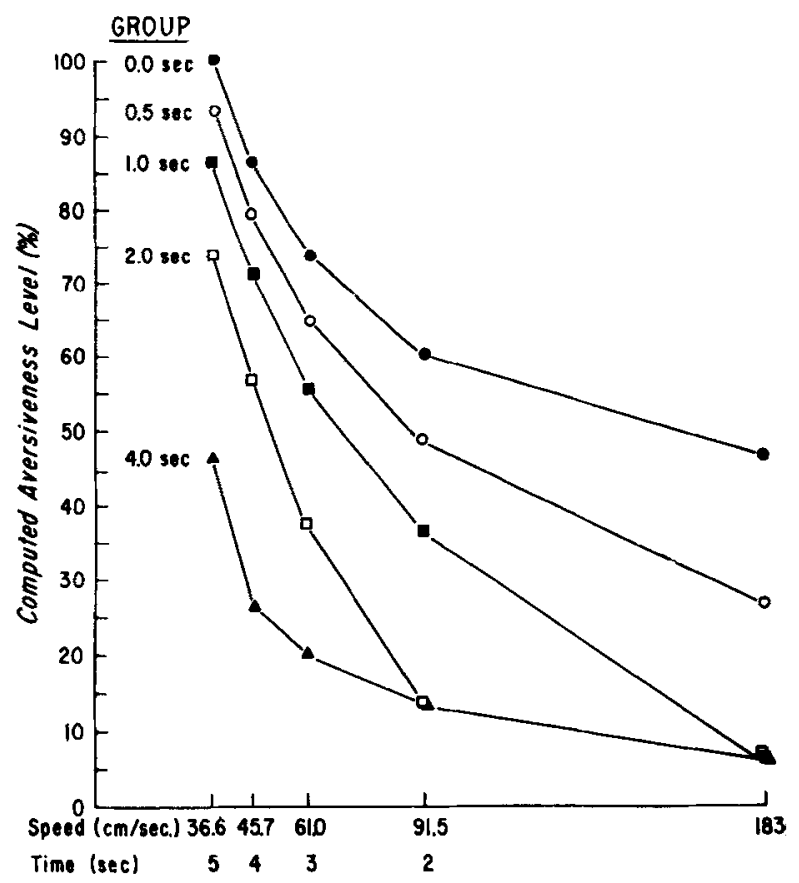

Fig. 2. Hypothetical aversiveness levels calculated for five shock-onset delay conditions and five possible running times in a $183-\mathrm{cm}$ alley. The 5-sec shock accompanying a 5-sec running time under a 0 -sec shock-onset delay was taken as $100 \%$. The lower levels of aversiveness produced by faster running, which reduced US duration, effective US length, and CS duration, were expressed as percentages of the maximum and averaged to obtain the plotted functions. steeper the slope of the function, the higher the likelihood that slow running will be weakened and fast running strengthened. At the end of acquisition, the running speeds in this study ranged from about $61 \mathrm{~cm} / \mathrm{sec}$ to $175 \mathrm{~cm} / \mathrm{sec}$. The slopes of the curves between these two points, therefore, should be most closely related to the performance levels of the groups. The computed differences in aversiveness percentages between 61 and $183 \mathrm{~cm} / \mathrm{sec}$ were, in order of size, 48.9 for the $1 \mathrm{sec}$ group, 37.8 for the $0.5-\mathrm{sec}$ group, 31.1 for the 2 -sec group, 26.7 for the 0 -sec group, and 13.3 for the 4-sec animals. Of special interest is the fact that the rank order of these differences corresponded exactly to the rank order of the speeds of the groups in the third segment on Days 2 through 10 (Fig. 1). On Days 2, 3, 4, 5,9 , and 10 , the group speeds in Segment 2 were also in the order derived from the model, and on Days 3,4 , and 5 , the Segment 1 data were likewise consistent with the predicted order. In addition, for every segment, all statistically significant terminal speed differences, as revealed by Scheffé tests, corresponded to the speed relations provided by the model.

In more general terms, it is evident that the two fastest groups $(0.5$ - and $1-\mathrm{sec})$ could effect response-contingent changes in all three of the aversiveness factors (US duration, CS duration, and effective US length) over the entire range of times from 5 to $1 \mathrm{sec}$. The intermediate group ( 0 -sec delay) could produce changes in only two of the aversiveness dimensions, US and CS duration; and the slow-running avoidance groups, though able to modify all three factors at running times longer than their avoidance criteria ( 2 and $4 \mathrm{sec}$ ), could affect only one factor-CS duration, at running times shorter than their criteria. The experimental findings are thus consistent with a common-sense version of the model, suggesting that the greater the number of sources of aversiveness that can be contingently altered by the animal's behavior, the better the performance.

It is obvious, of course, that many different factors must affect runway performance in this situation. The partial success of the proposed model, however, supports the idea that response-produced variations in aversiveness are among the most influential of those determinants. It should be noted that caluclations of relative CS duration and US duration based on times greater than $5 \mathrm{sec}$ and less than $60 \mathrm{sec}$ (the extinction criterion), would not change the group's rank orders. In addition, the assumption that CS duration affected all groups equally was made to simplify the model. For partial-avoidance and avoidance groups, proportional reductions in CS duration weighting might be made, since less fear conditioning to the alley cues might be expected with these groups as compared to the escape group. Such proportional reductions in CS weighting, up to about $30 \%$, do not change the rank orders generated by the model presented. Reductions in CS weighting greater than $30 \%$ generate "predictions" in 
which the relative positions of the $2-\mathrm{sec}$ and $0-\mathrm{sec}$ groups are inverted.

The finding that none of the $F$ ratios computed from percentage speed decreases during extinction was significant is perfectly consistent with the supposition that the declines during extinction were proportional to the level of performance at the start of extinction. Had the speeds of all groups exhibited equal proportional losses from their starting levels, the between-group comparisons based on these losses could not have been significant. However, equal percentage drops should have been accompanied by significant Groups by Days interactions in the analyses of median speeds. The lack of such interactions in the present study can be attributed, in part, to the inflated variances resulting from the extreme scores of extinguished Ss.

Finally, whereas no explicit CS was used in the present experiment, relatively discrete cues arising from being placed into the startbox, from being dropped into the alley from the startbox at the beginning of each trial, and the like, could have served as effective CSs along with, or in addition to, apparatus cues. Perhaps the high-level performance of the $1-$ and $0.5-\mathrm{sec}$ groups was partly due to their having had a more optimum CS-UCS interval for the conditioning of fear and for the maintenance of its strength. In this regard, as Brown (1969) has noted, the theory of self-punitive behavior developed by Mowrer (1960) may help to illuminate performance under the partial-avoidance paradigm.

\section{REFERENCES}

Baum, M., Jaffe, P. G., \& Leclerc, R. The effect of a loud buzzer upon the acquisition and extinction of a simple avoidance response in rats. Canadian Journal of Psychology, 1971, 25, 24-32.

Beecroft, R, S., \& Brown, J. S. Punishment following escape and avoidance training. Psychonomic Science, 1967, 8, 349-350.

Bitterman, M. E. Classical conditioning in the goldfish as a function of the CS-US interval. Journal of Comparative \& Physiological Psychology, 1964,58, 359-366.

Bitterman, M. E. The CS-US interval in classical and avoidance conditioning. In W. F. Prokasy (Ed.), Classical conditioning. New York: A ppleton-Century-Crofts, 1965.

Brown, J. S. Factors affecting self-punitive locomotor behavior. In B. Campbell and R. M. Church (Eds.), Punishment and aversive behavior. New York: Appleton-Century-Crofts, 1969.

Brown, J. S., Beier, E. M., \& Lewis, R. W. Punishment-zont distinctiveness and self-punitive locomotor behavior in the rat. Journal of Comparative \& Physiological Psychology, 1971, 77, 513-520

Low, L. A., \& Low, H. J. Effects of the CS-US interval length upon avoidance responding. Journal of Comparative \& Physiological Psychology, 1962, 55, 1059-1061.

Mowrer, O. H. Learning theory and behavior. New York: Wiley, 1960 .

(R eceived for publication March 1, 1974; revision accepted June 20,1974 .) 